\title{
Open-loop analysis on sympathetically mediated arterial pressure and urine output responses in spontaneously hypertensive rats: effect of renal denervation
}

\author{
Toru Kawada ${ }^{*} \oplus$, Takuya Nishikawa' ${ }^{2}$ Satoru Suehara², Satoshi Sawada ${ }^{2}$, Tetsuo Tanaka², Minako Uenohara ${ }^{2}$, \\ Hiromi Yamamoto ${ }^{3}$ and Masaru Sugimachi ${ }^{1}$
}

\begin{abstract}
Primary acute sympathetic activation (PASA) causes a subsequent arterial pressure (AP) elevation. In this case, an antidiuretic effect via the renal innervation and pressure diuresis can act antagonistically on the kidneys. We examined the effect of PASA on urine output in spontaneously hypertensive rats (SHR) 4-7 days after unilateral renal denervation (RDN) $(n=9)$. The slope of the plot of urine flow versus AP was positive $\left(0.120 \pm 0.031 \mu \mathrm{L} \mathrm{min}^{-1} \mathrm{~kg}^{-1} \mathrm{~mm} \mathrm{Hg}^{-1}\right)$ on the intact side, but it was less than 1/3 of the slope observed previously in normotensive Wistar-Kyoto rats (WKY). RDN did not normalize the slope of urine flow versus AP $\left(0.179 \pm 0.025 \mu \mathrm{L} \mathrm{min}^{-1} \mathrm{~kg}^{-1} \mathrm{mmHg}^{-1}, P=0.098\right.$ versus the intact side). The urine flow at the operating point of the AP tended to be greater on the denervated than the intact side (29.0 \pm 1.8 vs. $\left.25.3 \pm 1.9 \mu \mathrm{L} \mathrm{min}^{-1} \mathrm{~kg}^{-1}, P=0.055\right)$. The percent increase $(17.2 \pm 7.2 \%)$ was not different from that observed previously in WKY. Although high-resting sympathetic nerve activity is prerequisite for maintaining hypertension in SHR, the effect of sympathetic innervation on the urine output function was not greater than that in WKY.
\end{abstract}

Keywords: Pressure diuresis, Sympathetic nerve activity, Arterial pressure, Open-loop analysis, Equilibrium diagram

\section{Background}

Urine output control is essential for the long-term regulation of arterial pressure (AP). A decrease in urine output promotes body fluid retention and contributes to the increase of AP, and vice versa. Renal sympathetic activation exerts an antidiuretic effect via the release of renin, renal vasoconstriction, and sodium and water reabsorption [1]. It has been shown that renal sympathetic activation reduces urine output under a constant renal perfusion pressure in anesthetized dogs [2]. However, the relationship between sympathetic nerve activity (SNA)

*Correspondence: torukawa@ncvc.go.jp

${ }^{1}$ Department of Cardiovascular Dynamics, National Cerebral and Cardiovascular Center, Osaka 564-8565, Japan

Full list of author information is available at the end of the article and urine output may not always be negative. During primary acute sympathetic activation (PASA) that induces a subsequent AP elevation, an increase in renal perfusion pressure can promote diuresis and antagonize the antidiuretic effect via renal sympathetic innervation.

In a previous study, we demonstrated that the urine output positively correlated with SNA during PASA in normotensive Wistar-Kyoto rats (WKY) [3]. It was concluded that the pressure diuresis mechanism outweighs the antidiuretic effect mediated by the renal sympathetic nerve during PASA. In that study, unilateral renal denervation (RDN) caused a higher urine output at the operating point of AP in the denervated than in the intact kidney. Sympathetic activation is one of the key factors of the pathogenesis of hypertension. We hypothesized that the contribution of the renal sympathetic control to the

c) The Author(s) 2021. This article is licensed under a Creative Commons Attribution 4.0 International License, which permits use, sharing, adaptation, distribution and reproduction in any medium or format, as long as you give appropriate credit to the original author(s) and the source, provide a link to the Creative Commons licence, and indicate if changes were made. The images or other third party material in this article are included in the article's Creative Commons licence, unless indicated otherwise in a credit line to the material. If material is not included in the article's Creative Commons licence and your intended use is not permitted by statutory regulation or exceeds the permitted use, you will need to obtain permission directly from the copyright holder. To view a copy of this licence, visit http://creativeco mmons.org/licenses/by/4.0/. 
urine output function would be greater in spontaneously hypertensive rats (SHR). If so, the urine output increase by RDN would be augmented in SHR. To test the hypothesis, we examined the urine output change during PASA induced by baroreceptor pressure inputs in anesthetized SHR. The experiment was performed on SHR 4-7 days after unilateral RDN, and the urine output was compared between the intact and denervated sides.

\section{Methods}

\section{Ethical approval}

Male SHR were purchased from Japan SLC at 12 weeks of age. The rats were cared for in strict accordance with the Guiding Principles for the Care and Use of Animals in the Field of Physiological Sciences, which has been approved by the Physiological Society of Japan. The Animal Subjects Committee at the National Cerebral and Cardiovascular Center reviewed and approved all experimental protocols.

\section{Renal denervation}

Unilateral RDN was performed on nine rats under isoflurane anesthesia using a sterile preparation. Through a flank incision, visible renal nerves were sectioned under a dissecting microscope, and a solution of $10 \%$ phenol in ethanol was applied around the renal vessels [4]. The incision was closed, and butorphanol tartrate was injected intramuscularly for postoperative analgesia. Six rats underwent a right RDN procedure, and remaining three rats underwent a left RDN procedure. If the observed difference in the urine output function was attributed solely to the laterality, the inclusion of data from the denervation on the different side would have canceled the statistical difference. After the unilateral RDN, each rat was housed individually and given free access to standard laboratory chow and water.

At the end of the acute experiment described below, tissue samples obtained from the kidneys (100-200 mg) were frozen at $-80{ }^{\circ} \mathrm{C}$. Later, the tissue norepinephrine concentration was measured with a high-performance liquid chromatography system (Eicom, Japan). We defined the RDN as successful when norepinephrine was depleted to less than $10 \%$ in the denervated side relative to the intact side. All nine rats met this criterion (0.3-9.0\%).

\section{Preparation of acute experiment}

Four-to-seven days after the RDN, the rats (295-338 g) were anesthetized by intraperitoneal injection $(2 \mathrm{~mL} / \mathrm{kg})$ of a mixture of urethane $(250 \mathrm{mg} / \mathrm{mL})$ and $\alpha$-chloralose $(40 \mathrm{mg} / \mathrm{mL})$. For the maintenance of anesthesia, an 18 -fold diluted solution of the anesthetic mixture was administered $\left(2 \mathrm{~mL} \mathrm{~kg}^{-1} \mathrm{~h}^{-1}\right)$ via the right femoral vein.
Ringer's lactate solution was also infused $\left(4 \mathrm{~mL} \mathrm{~kg}^{-1} \mathrm{~h}^{-1}\right)$ via the left femoral vein for fluid maintenance. Systemic AP was measured via a polyethylene catheter (PE50, Becton Dickinson and Company, MD, USA) that was inserted into the right femoral artery. Heart rate (HR) was detected from the AP waveform. The rats were mechanically ventilated with oxygen-enriched room air. The body temperature of the rat was maintained at approximately $38^{\circ} \mathrm{C}$ with a heating pad and a lamp.

As a proxy of systemic SNA, the splanchnic sympathetic nerve was selected, because the control of splanchnic vascular bed plays an essential role in systemic AP regulation [5]. A pair of stainless-steel wire electrodes (AS633, Cooner Wire, CA, USA) were attached to a postganglionic branch of the left splanchnic sympathetic nerve and fixed with silicone glue (Kwik-Sil, World Precision Instruments, FL, USA). The SNA was quantified via full-wave rectification and low-pass filtering with a cutoff frequency of $30 \mathrm{~Hz}$. At the end of the experiment, a ganglionic blocker hexamethonium bromide $(60 \mathrm{mg} / \mathrm{kg})$ was injected intravenously to assess the noise level of the SNA recording.

Before isolating the carotid sinus baroreceptor regions, we measured AP and HR for more than $5 \mathrm{~min}$. Thereafter, bilateral carotid sinus baroreceptor regions were isolated from the systemic circulation [6, 7], and carotid sinus pressure (CSP) was controlled with a servo-controlled piston-pump system (ET-126, Labworks, Costa Mesa, CA, USA). The aortic depressor nerves and vagal nerves were sectioned bilaterally to prevent reflexes other than the carotid sinus baroreflex from confounding the results.

A polyethylene tube (KN-392-SP 8, inner diameter: $0.2 \mathrm{~mm}$, outer diameter: $0.5 \mathrm{~mm}$, Natsume, Japan) was inserted into each ureter via a horizontal abdominal incision. Urine from each ureter was collected in a 1-mL syringe placed vertically on the lateral side of a surgical table. The top of the syringe was positioned just below the surface of the table [3]. The urine volume was calculated based on the hydrostatic pressure of the collected urine relative to that of 1-mL physiological saline.

\section{Protocol of acute experiment}

The CSP was first decreased to $60 \mathrm{mmHg}$ and increased stepwise up to $220 \mathrm{mmHg}$ in $20 \mathrm{mmHg}$ increments. The CSP step duration was either 60 or $90 \mathrm{~s}$, which was longer than the total response time of the urine flow (UF) change during a short-term AP perturbation in rats (17.6-26.7 s) [8]. The CSP step input was repeated twoto-three times.

The fluid maintenance started after the venous catheterization, and the entire surgical preparation lasted approximately $90 \mathrm{~min}$. After the completion of the 
surgical preparation, another $30 \mathrm{~min}$ was allowed before the CSP step input protocol was initiated. Hence, the differences in the hydration status among rats might have reduced, if not completely disappeared.

\section{Blood, urine, and renal tissue samples}

A blood sample was extracted at the end of the acute experiment. After centrifugation, the plasma was frozen at $-80{ }^{\circ} \mathrm{C}$. Cumulated urine from each kidney was also frozen at $-80{ }^{\circ} \mathrm{C}$. The sodium and creatinine concentrations of the plasma and urine samples were measured (Hachioji Laboratories, SRL Inc., Japan).

\section{Data analysis}

Data were stored at $1000 \mathrm{~Hz}$ on a laboratory computer system via a 16-bit analog-to-digital converter. The mean SNA and AP values at each CSP level were calculated during the last $10 \mathrm{~s}$ of each step. The mean values at the same CSP level from the multiple CSP step inputs were then averaged. The SNA was normalized with the value at CSP of $60 \mathrm{mmHg}(100 \%)$ and the value after the ganglionic blockade ( $0 \%$ ). The UF (in $\mu \mathrm{L} / \mathrm{min}$ ) at each step was derived from the increment of the urine volume from the preceding step. When the step duration was $90 \mathrm{~s}$, the increment was divided by 1.5 . The normalized urine flow (nUF, in $\mu \mathrm{L} \mathrm{min}{ }^{-1} \mathrm{~kg}^{-1}$ ) was defined as the UF value divided by the body weight of the rat.

The total reflex arc (the AP change as a function of CSP) and the neural arc (the SNA change as a function of CSP) were quantified by fitting a four-parameter logistic function to the data [9]:

$$
y=\frac{P_{1}}{1+\exp \left[\mathrm{P}_{2}\left(\mathrm{CSP}-\mathrm{P}_{3}\right)\right]}+P_{4},
$$

where $P_{1}$ is the response range, $P_{2}$ is the slope coefficient, $P_{3}$ is the midpoint pressure on the CSP axis, and $P_{4}$ is the lower plateau of the sigmoid curve.

The peripheral arc (the AP change as a function of SNA) was quantified by linear regression. The operating-point SNA and AP values were estimated from the intersection point between the fitted neural and peripheral arcs on a baroreflex equilibrium diagram [10-12].

The SNA-nUF relationship and the AP-nUF relationship were also quantified by linear regression. The nUF at the operating-point AP, which was estimated on the regression line of the AP-nUF relationship, was used to calculate creatinine clearance in each kidney. Fractional sodium excretion was calculated from the creatinine and sodium concentrations in the plasma and cumulated urine.

\section{Statistical analysis}

The data are expressed as mean \pm SE values. Differences between the intact and denervated sides were examined using the Wilcoxon signed-rank test [13]. In the discussion section, we also performed statistical comparisons of the data between SHR in the present study $(n=9)$ and WKY in our previous study $(n=10)$ using the Mann-Whitney test. The difference was considered significant at $P<0.05$.

\section{Results}

Typical time-series obtained in one rat are shown in Fig. 1. Increasing CSP up to $140 \mathrm{mmHg}$ did not affect SNA or AP. Increasing CSP above $140 \mathrm{mmHg}$ caused SNA suppressions, but the mean SNA remained at approximately $50 \%$ in response to the CSP of $220 \mathrm{mmHg}$. The AP reductions were observed in response to the CSP steps above $140 \mathrm{mmHg}$, but the response to each step was not maintained during the $90 \mathrm{~s}$ step duration. The urine volume in the intact side increased nearly linearly with time. The urine volume was greater on the denervated than the intact side, and the difference increased as time elapsed. The urine volume in the denervated side showed low-frequency fluctuation that did not seem to be related to AP changes. This fluctuation was not a consistent observation across rats and disappeared during the analysis of pooled data.

Figure 2 and Table 1 summarize the open-loop static characteristics of the carotid sinus baroreflex. The total reflex arc (Fig. 2a) and the neural arc (Fig. 2b) approximated inverse sigmoid curves. The maximum SNA occurred at CSP steps in the range of $80-120 \mathrm{mmHg}$, and slightly exceeded $100 \%$, because SNA at the CSP of $60 \mathrm{mmHg}$ was defined to be $100 \%$. The peripheral arc (Fig. 2c) approximated a straight line. In the baroreflex equilibrium diagram (Fig. 2d), the intersection between the neural and peripheral arcs provided the operating point.

The SNA and nUF showed a positive correlation on both sides (Fig. 2e), and the regression slope tended to be greater on the denervated side (Table 2). The AP and nUF also showed a positive correlation on both sides (Fig. 2f). The regression slope of the AP-nUF relationship did not differ significantly between the intact and denervated sides. The vertical dotted line in Fig. $2 f$ denotes the operating point of the AP estimated from the equilibrium diagram. The nUF at the operatingpoint AP, depicted in the leftward arrowhead, tended to be higher on the denervated than the intact side (Table 2). The percent increase of the nUF at the operating-point AP induced by RDN was $17.2 \pm 7.2 \%$. 

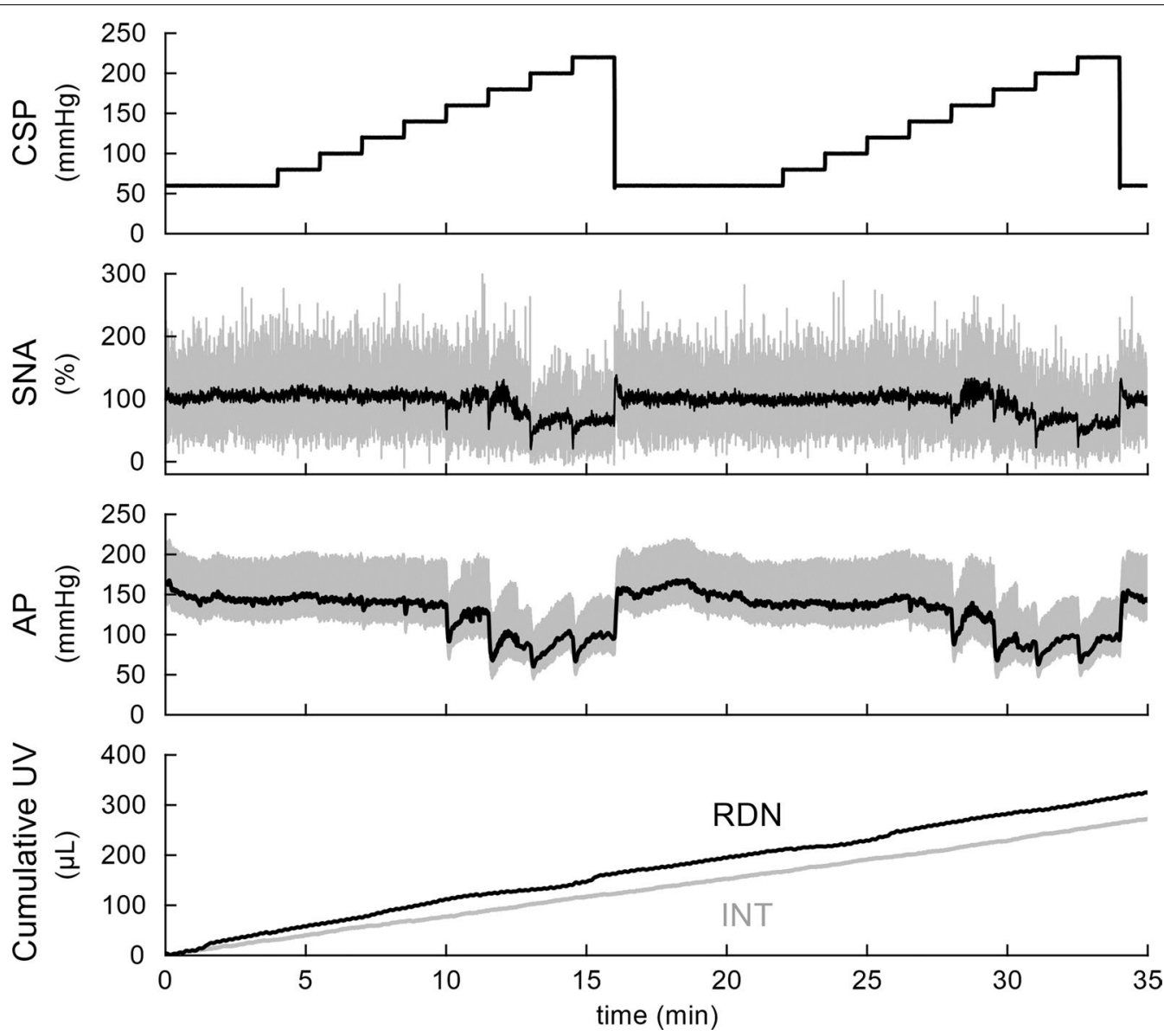

Fig. 1 An example time-series obtained from one rat. The carotid sinus pressure (CSP) was changed in a stepwise manner with a step duration of 90 s. Sympathetic nerve activity (SNA) and arterial pressure (AP) decreased in response to CSP when the CSP was above $140 \mathrm{mmHg}$. Gray and black lines in the SNA plot indicate 10-Hz resampled and 2-s moving average signals, respectively. Gray and black lines in the AP plot indicate 200-Hz resampled and 2-s moving average signals, respectively. Urine volume (UV) is displayed as a 10-Hz resampled signal. The UV was greater on the renal denervation (RDN) side compared with the intact (INT) side, and the difference increased as time elapsed

Sodium and creatinine concentrations in the plasma and the cumulated urine were measured in eight out of nine rats (Table 3). Creatinine clearance, calculated using the nUF at the operating-point AP, did not differ significantly between the intact and denervated sides $\left(2508 \pm 277\right.$ vs. $2769 \pm 485 \mu \mathrm{L} \min ^{-1} \mathrm{~kg}^{-1}, P=0.547$, $n=8)$. Fractional sodium excretion did not differ significantly between the intact and denervated sides $(0.54 \pm 0.16 \%$ vs. $0.73 \pm 0.24 \%, P=0.195, n=8)$.

\section{Discussion}

\section{Sympathetic activation and urine output response}

Neural control of the kidney through renal innervation is important for body fluid volume control. Renal sympathetic activation exerts an antidiuretic effect via the release of renin, renal vasoconstriction, and sodium and water reabsorption [1]. During a hypotensive event, such as that induced by hemorrhage, a decrease in renal perfusion pressure and a baroreflex-mediated sympathetic activation act synergistically to reduce urine output and promote fluid retention. By contrast, an increase in renal perfusion pressure due to an AP elevation following PASA can counteract the antidiuretic effect via renal sympathetic innervation. We have demonstrated that urine output from the innervated kidney increases with SNA during PASA in WKY [3]. If the antidiuretic effect via renal innervation in SHR is powerful enough compared with systemic sympathetic control of the AP, the urine output could be reduced with increasing SNA during PASA. However, nUF on the intact side positively correlated with SNA during PASA in SHR (Fig. 2e). Hence, the pressure diuresis resulting from an AP elevation following PASA outweighed the antidiuretic effect via renal efferent innervation not only in WKY but also in SHR. The slope values of the SNA-nUF relationship were not directly compared between SHR and WKY, because 

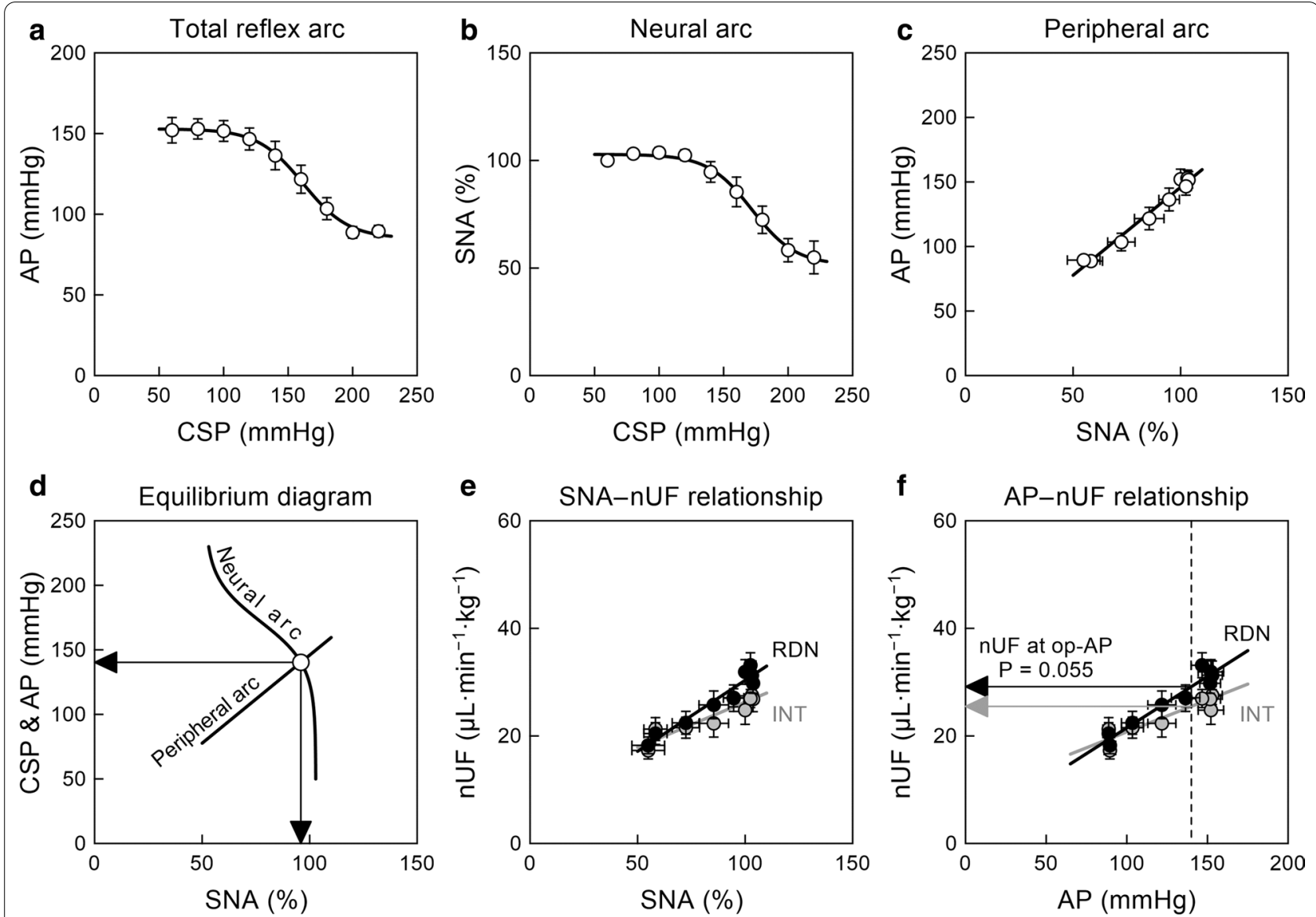

Fig. 2 a-c Group-averaged static characteristics of the total reflex arc, neural arc, and peripheral arc, respectively, of the carotid sinus baroreflex. CSP, carotid sinus pressure; AP, arterial pressure; SNA, sympathetic nerve activity. $\mathbf{d}$ The baroreflex equilibrium diagram constructed from the fitted neural and peripheral arcs. Downward and leftward arrowheads indicate the operating points of SNA and AP, respectively. e The relationship of normalized urine flow (nUF) versus SNA in the intact (INT) and renal denervation (RDN) sides. f The relationship of nUF versus AP in the INT and RDN sides. The vertical dashed line indicates the operating-point AP (op-AP). The horizontal arrowheads indicate nUF at op-AP. The P value was determined by the Wilcoxon signed-rank test. Data are expressed as mean \pm SE values ( $n=9$ rats)

the normalization of SNA could complicate the interpretation of the slope.

Sympathetic activation in SHR compared with WKY is to be briefly discussed. The carotid sinus baroreflex function in SHR resets to a higher input pressure range [14], which is confirmed by the high midpoint pressure in the neural arc (Table 1). Although high-CSP inputs can usually reduce SNA to approximately $10 \%$ or less in WKY [3, $15]$, the lower plateau of the neural arc was above $50 \%$ in the present study that suggests an incomplete sympathetic suppression in SHR. Furthermore, reductions of SNA and AP in response to the CSP step changes were transient compared with more sustained reductions observed in WKY [3]. The sustained AP reduction is mediated via the central pathway of unmyelinated C-fiber baroreceptors [16]. There are significantly fewer C-fiber baroreceptor axons in SHR compared with WKY [17], and nonderivative dynamic characteristics of the $\mathrm{C}$-fiber central pathway are compromised in SHR [18]. As a result, SNA and AP did not show sustained responses to the CSP step changes in SHR. Nevertheless, the lower plateau of the total reflex arc was $87 \mathrm{mmHg}$ (Table 1). Hence, the baroreflex-mediated sympathetic suppression can reduce AP to a normal pressure range in SHR if the baroreceptors are activated at adequately high pressures. Ganglionic blockade reduces AP in SHR to the same level as that in WKY [15], which further suggests that hypertension in SHR depends on high-resting SNA.

The slope of the AP-nUF relationship on the intact side was positive in SHR (Fig. 2f, Table 2), but the mean slope was less than $1 / 3$ of that in WKY observed in our previous study $\left(0.420 \pm 0.081 \mu \mathrm{L} \mathrm{min}{ }^{-1} \mathrm{~kg}^{-1} \mathrm{mmHg}^{-1}\right.$, $P=0.013$ by the Mann-Whitney test) [3]. If the slope difference is mainly attributed to the ongoing neural control over the kidney, the slope on the denervated side may be comparable between SHR and WKY. However, 
Table 1 Parameters of the carotid sinus baroreflex open-loop characteristics

\begin{tabular}{lc}
\hline Total reflex arc & \\
$P_{1}$, response range, $\mathrm{mmHg}$ & $67.0 \pm 7.7$ \\
$P_{2}$, slope coefficient, $\mathrm{mmHg}^{-1}$ & $0.117 \pm 0.026$ \\
$P_{3}$, midpoint pressure, $\mathrm{mmHg}$ & $155.2 \pm 6.3$ \\
$P_{4}$, minimum pressure, $\mathrm{mmHg}$ & $87.0 \pm 3.6$ \\
Neural arc & \\
$P_{1}$, response range, $\%$ & $52.9 \pm 8.1$ \\
$P_{2}$, slope coefficient, $\mathrm{mmHg}^{-1}$ & $0.102 \pm 0.020$ \\
$P_{3}$, midpoint pressure, $\mathrm{mmHg} \mathrm{Hg}$ & $165.7 \pm 5.8$ \\
$P_{4}$ minimum value, $\%$ & $51.2 \pm 7.9$ \\
Peripheral arc & \\
Intercept, mmHg & $1.6 \pm 24.1$ \\
Slope, mmHg/\% & $1.448 \pm 0.233$ \\
Operating-point parameters & \\
Operating-point SNA, \% & $94.9 \pm 3.8$ \\
Operating-point AP, mmHg & $138.3 \pm 5.1$ \\
\hline
\end{tabular}

Data are expressed as mean $\pm \mathrm{SE}$ ( $n=9$ rats)

$S N A$ sympathetic nerve activity, $A P$ arterial pressure

the slope of the AP-nUF relationship on the denervated side in SHR (Table 2) remained less than $1 / 3$ of that in WKY $\left(0.552 \pm 0.112 \mu \mathrm{L} \mathrm{min}{ }^{-1} \mathrm{~kg}^{-1} \mathrm{mmHg}^{-1}, P=0.001\right.$ by the Mann-Whitney test) [3]. Hence, the lower slope of the AP-nUF relationship in SHR compared with WKY is unlikely caused by the ongoing high renal SNA. The results are consistent with an earlier study that compared the effect of renal perfusion pressure on the UF in a denervated kidney between SHR and WKY [19]. The percent increase in nUF at the operating-point AP induced by RDN was not significantly different from that observed in WKY in our previous study $(14.7 \pm 6.0 \%, P=0.780$ by the Mann-Whitney test) [3].

The depression of renal function in SHR was not detected from the creatinine clearance and fractional sodium excretion, because these values were similar to those observed in WKY [3]. The results are in line with a previous study that indicated lack of significant
Table 3 Sodium and creatinine concentrations in plasma and urine

\begin{tabular}{lcccc}
\hline & Plasma & INT Urine & RDN Urine & $P$ value \\
\hline Sodium, $\mathrm{mEq} / \mathrm{L}$ & $140.9 \pm 1.0$ & $55.8 \pm 8.0$ & $61.5 \pm 9.0$ & 0.382 \\
Creatinine, $\mathrm{mg} / \mathrm{dL}$ & $0.30 \pm 0.01$ & $29.3 \pm 3.9$ & $26.8 \pm 4.0$ & 0.250
\end{tabular}

Data are expressed as mean $\pm \mathrm{SE}$ ( $n=8$ rats). INT, intact side; RDN, renal denervation side. $P$ values were calculated by the Wilcoxon signed-rank test between urine values from INT and RDN sides

differences in glomerular filtration rate or fractional sodium excretion between SHR and WKY at 14 weeks of age [20].

\section{RDN and hypertension}

Although RDN has been explored as a device therapy for resistant hypertension, a blinded, randomized, shamcontrolled trial SYMPLICITY HTN-3 did not show a significant reduction of systolic blood pressure (SBP) in patients with resistant hypertension 6 months after RDN as compared with those who underwent a sham procedure [21]. Although the reason for the lack of significant effects of RDN might be multifactorial, incomplete RDN was suspected [22]. A newer trial, SPYRAL HTN-OFF MED Pivotal, which used an improved device to achieve thorough and consistent RDN, demonstrated a significant SBP reduction in a denervated group compared with a sham procedure group in the absence of antihypertensive medications [23]. However, the reduction of 24-h SBP at 3 months after RDN was between -6.4 and $-2.9 \mathrm{mmHg}$ (95\% confidence interval). Given that the pathophysiology of hypertension is heterogeneous, RDN may not be a panacea for all hypertensive patients [24]. It is necessary to identify subgroups of patients who benefit maximally from RDN based on an understanding of the effect of RDN on the AP regulation.

Since we did not prepare a proper control group of sham-operated SHR, whether unilateral RDN reduced AP was inconclusive in the present study. Five-min averaged AP and HR values measured under anesthesia but before the baroreceptor isolation procedure were

Table 2 Effects of unilateral renal denervation (RDN) on normalized urine flow (nUF)

\begin{tabular}{|c|c|c|c|}
\hline & INT & RDN & $P$ value \\
\hline Slope of nUF versus SNA, $\mu \mathrm{L} \mathrm{min}^{-1} \mathrm{~kg}^{-1} \%^{-1}$ & $0.168 \pm 0.042$ & $0.264 \pm 0.059$ & 0.055 \\
\hline Intercept of nUF versus SNA, $\mu \mathrm{L}$ min $^{-1} \mathrm{~kg}^{-1}$ & $9.2 \pm 3.8$ & $3.8 \pm 5.3$ & 0.301 \\
\hline Slope of nUF versus AP, $\mu \mathrm{L} \mathrm{min}^{-1} \mathrm{~kg}^{-1} \mathrm{mmHg}^{-1}$ & $0.120 \pm 0.031$ & $0.179 \pm 0.025$ & 0.098 \\
\hline Intercept of nUF versus $\mathrm{AP}, \mu \mathrm{L} \mathrm{min}-1 \mathrm{~kg}^{-1}$ & $9.4 \pm 3.6$ & $4.4 \pm 3.0$ & 0.301 \\
\hline nUF at the operating-point $A P, \mu L \min ^{-1} \mathrm{~kg}^{-1}$ & $25.3 \pm 1.9$ & $29.0 \pm 1.8$ & 0.055 \\
\hline
\end{tabular}

Data are expressed as mean \pm SE ( $n=9$ rats). INT, intact side; SNA, sympathetic nerve activity; AP, arterial pressure. P values were calculated by the Wilcoxon signedrank test 
$178.7 \pm 8.7 \mathrm{mmHg}$ and $417.3 \pm 15.3$ beats $/ \mathrm{min}$, respectively $(n=9)$. As a reference, the 5 -min averaged AP and $H R$ values measured under similar settings were $195.7 \pm 4.9 \mathrm{mmHg}$ and $421.8 \pm 11.3$ beats $/ \mathrm{min}$, respectively, in SHR without any prior operation $(n=12$, randomly selected from our past studies). While the mean AP in SHR with unilateral RDN was numerically lower than that in SHR without any prior operation, the difference was not statistically significant by the MannWhitney test $(P=0.177)$. The difference in HR was not statistically significant, either $(P=0.722)$.

Although unilateral RDN has the merit that we can compare the urine output function between the intact and denervated kidneys under the same perfusion pressure and circulating humoral factors, it cannot provide information on the effect of bilateral RDN. Gao et al. [25] demonstrated that bilateral radiofrequency renal artery denervation in SHR with established hypertension produced a sustained reduction of SBP $(171 \pm 6 \mathrm{mmHg})$ compared with sham control $(183 \pm 4 \mathrm{mmHg})$ at 8 weeks after RDN. While the effect of renal artery denervation was significant, AP remained higher than the normal pressure range. An earlier study indicated that bilateral RDN in SHR delayed the development of hypertension by approximately 2 weeks, but did not affect the final AP level compared with sham-operated SHR [26]. In another study, bilateral RDN performed at 13 weeks of age reduced SBP of SHR [27]. However, SBP of SHR with bilateral RDN increased gradually beginning 21 weeks after RDN and reached a level equivalent to SBP of sham-operated SHR at 35 weeks after RDN. At this time point (48 weeks of age), plasma renin activity (PRA) of sham-operated SHR was higher than that of WKY. By contrast, PRA of SHR with bilateral RDN was reduced to a level comparable to WKY [27]. Hence, the reduction of PRA by bilateral RDN did not prevent the eventual development of hypertension in SHR.

A kidney cross-transplantation study indicated that normotensive recipients of SHR kidneys developed hypertension, and that the transplantation of normotensive kidneys reduced the blood pressure of hypertensive recipients [28]. These results suggest that kidneys have a fundamental role in the development of hypertension in SHR. One of the potential mechanisms for the impaired diuresis in SHR kidneys is a defect in dopamine receptor signaling [29]. Dopamine produced by renal proximal tubules serves as an intrarenal natriuretic hormone by decreasing tubular sodium transport. SHR kidneys show uncoupling between the $\mathrm{D}_{1}$-like receptor and its effector enzyme complex in proximal tubules, leading to a failure of dopamine to inhibit proximal tubular luminal sodium/ hydrogen exchanger and sodium/potassium ATPase activity. Chronic inhibition of dopamine biosynthesis accelerates the development of hypertension in SHR [30].

It remains difficult to reconcile a) the fundamental role of the kidneys in developing hypertension in SHR and b) the fact that high-resting SNA may be required for maintaining hypertension in SHR. One possible explanation is that renal afferent signaling from the damaged kidney to the brain evokes systemic sympathetic activation [22]. Electrical stimulation of the renal afferent nerve activates neurons in the paraventricular nucleus projecting to the rostral ventrolateral medulla that serves as a center of sympathetic outflow [31]. However, the renal afferent mechanism alone may not be able to explain why SHR kidneys transplanted into normotensive recipients develop hypertension despite the total denervation. It has been shown that an increase in the sodium concentration in cerebrospinal fluid precedes an increase in AP induced by high-salt diet in SHR and Dahl salt-sensitive rats [32]. The plasma sodium concentration was not significantly different between SHR and WKY or between regular- and high-salt diets in that study. Given that pressure-dependent renal sodium excretion was depressed in parallel with renal urine output function in SHR compared with WKY [19], the difference in sodium handling-even though it is not reflected in the plasma sodium concentration-may cause central effects that increase SNA in SHR. A caveat to this interpretation is that the sodium concentration in cerebrospinal fluid is not different between WKY and SHR during regular-salt diet [32].

\section{Conclusions}

The present study demonstrated that PASA increased urine output in SHR. Although sympathetic activation is generally considered to promote body fluid volume retention, sympathetic activation, when it accompanies an AP elevation, may promote urine output against the depressed renal urine output function in SHR. The percent increase in the nUF at the operating-point $\mathrm{AP}$ induced by the RDN was not different from that observed previously in WKY. Although high-resting SNA is required to maintain hypertension in SHR, its effect on the urine output function was not more potent than that in WKY.

\footnotetext{
Abbreviations

AP: Arterial pressure; CSP: Carotid sinus pressure; HR: Heart rate; nUF: Normalized urine flow; PASA: Primary acute sympathetic activation; RDN: Renal denervation; PRA: Plasma renin activity; SBP: Systolic blood pressure; SHR: Spontaneously hypertensive rats; SNA: Sympathetic nerve activity; UF: Urine flow; WKY: Wistar-Kyoto rats.

Acknowledgements

None.
} 


\section{Authors' contributions}

TK and MS conceived and designed the study. TK performed the experiments and analyzed data. $\mathrm{TK}, \mathrm{TN}, \mathrm{SS}^{\mathrm{a}}, \mathrm{SS}^{\mathrm{b}}, \mathrm{TT}, \mathrm{MU}, \mathrm{HY}$, and MS interpreted the results of the experiments. TK prepared the figures and drafted the manuscript. TK and MS edited and revised the manuscript. All authors read and approved the final manuscript (Satoru Suehara ${ }^{a}$, Satoshi Sawada ${ }^{b}$ )

\section{Funding}

This study was partly supported by Grants-in-Aid for Scientific Research (JSPS KAKENHI grants 18K06451, 18K10695, and 20K20622) and by the Salt Science Research Foundation (No. 1921, 2029). The authors confirm that the funders had no influence over the study design, contents of the article, or selection of this journal.

\section{Availability of data and materials}

The datasets used and/or analyzed during the current study are available from the corresponding author on reasonable request.

\section{Declarations}

\section{Ethics approval and consent to participate}

The rats were cared for in strict accordance with the Guiding Principles for the Care and Use of Animals in the Field of Physiological Sciences, which has been approved by the Physiological Society of Japan. The Animal Subjects Committee at the National Cerebral and Cardiovascular Center reviewed and approved all experimental protocols.

\section{Consent for publication}

Not applicable.

\section{Competing interests}

The authors declare no conflict of interest regarding this study.

\section{Author details}

1 Department of Cardiovascular Dynamics, National Cerebral and Cardiovascular Center, Osaka 564-8565, Japan. ${ }^{2}$ Corporate R\&D Center, Terumo Corporation, Kanagawa 259-0151, Japan. ${ }^{3}$ Department of Cardiology, Kurashiki Central Hospital, Ohara HealthCare Foundation, Okayama 710-8602, Japan.

Received: 16 October 2020 Accepted: 31 March 2021

Published online: 20 April 2021

\section{References}

1. Jackson EK (2004) Autonomic control of the kidney. In: Robertson D (ed) Primer on the autonomic nervous system, 2nd edn. Elsevier Academic Press, San Diego, pp 157-161

2. Beers ET, Carroll RG, Young DB, Guyton AC (1986) Effects of graded changes in reflex renal nerve activity on renal function. Am J Physiol 250:F559-F565. https://doi.org/10.1152/ajprenal.1986.250.3.F559

3. Kawada T, Hayama Y, Nishikawa T, Suehara S, Sawada S, Tanaka T, Uenohara M, Sugimachi M (2020) Open-loop analysis on sympathetically mediated arterial pressure and urine output responses in rats: effect of renal denervation. J Physiol Sci 70:32. https://doi.org/10.1186/ s12576-020-00759-w

4. Herlitz H, Ricksten SE, Lundin S, Thorén P, Aurell M, Berglund G (1983) Renal denervation and sodium balance in young spontaneously hypertensive rats. Ren Physiol 6:145-150. https://doi.org/10.1159/000172893

5. Brooksby GA, Donald DE (1971) Dynamic changes in splanchnic blood flow and blood volume in dogs during activation of sympathetic nerves. Circ Res 29:227-238. https://doi.org/10.1161/01.res.29.3.227

6. Shoukas AA, Callahan CA, Lash JM, Haase EB (1991) New technique to completely isolate carotid sinus baroreceptor regions in rats. Am J Physiol 260:H300-H303. https://doi.org/10.1152/ajpheart.1991.260.1.H300

7. Sato T, Kawada T, Miyano H, Shishido T, Inagaki M, Yoshimura R, Tatewaki T, Sugimachi M, Alexander J Jr, Sunagawa K (1999) New simple methods for isolating baroreceptor regions of carotid sinus and aortic depressor nerves in rats. Am J Physiol 276:H326-H332. https://doi.org/10.1152/ ajpheart.1999.276.1.H326
8. Steele JE, Brand PH, Metting PJ, Britton SL (1993) Dynamic, short-term coupling between changes in arterial pressure and urine flow. Am J Physiol 265:F717-F722. https://doi.org/10.1152/ajprenal.1993.265.5.F717

9. Kent BB, Drane JW, Blumenstein B, Manning JW (1972) A mathematical model to assess changes in baroreceptor reflex. Cardiology 57:295-310. https://doi.org/10.1159/000169528

10. Mohrman D, Heller L (2010) Cardiovascular Physiology, 7th edn. McGrawHill, New York, pp 246-250

11. Sato T, Kawada T, Inagaki M, Shishido T, Takaki H, Sugimachi M, Sunagawa K (1999) New analytic framework for understanding sympathetic baroreflex control of arterial pressure. Am J Physiol 276:H2251-H2261. https:// doi.org/10.1152/ajpheart.1999.276.6.H2251

12. Kawada T, Sugimachi M (2016) Open-loop static and dynamic characteristics of the arterial baroreflex system in rabbits and rats. J Physiol Sci 66:15-41. https://doi.org/10.1007/s12576-015-0412-5

13. Glantz SA (2002) Primer of biostatistics, 5th edn. McGraw-Hill, New York, pp 354-362

14. Nosaka S, Wang SC (1972) Carotid sinus baroreceptor functions in the spontaneously hypertensive rats. Am J Physiol 222:1079-1084. https:// doi.org/10.1152/ajplegacy.1972.222.5.1079

15. Sata Y, Kawada T, Shimizu S, Kamiya A, Akiyama T, Sugimachi M (2015) Predominant role of neural arc in sympathetic baroreflex resetting of spontaneously hypertensive rats. Circ J 79:592-599. Doi: https://doi.org/ 10.1253/circj.CJ-14-1013

16. Turner MJ, Kawada T, Shimizu S, Sugimachi M (2014) Sustained reduction in blood pressure from electrical activation of the baroreflex is mediated via the central pathway of unmyelinated baroreceptors. Life Sci 106:40-49. https://doi.org/10.1016/j.lfs.2014.04.016

17. Fazan VP, Salgado HC, Barreira AA (2001) Aortic depressor nerve unmyelinated fibers in spontaneously hypertensive rats. Am J Physiol Heart Circ Physiol 280:H1560-H1564. https://doi.org/10.1152/ajpheart.2001.280.4. H1560

18. Turner MJ, Kawada T, Shimizu S, Fukumitsu M, Sugimachi M (2015) Differences in the dynamic baroreflex characteristics of unmyelinated and myelinated central pathways are less evident in spontaneously hypertensive rats. Am J Physiol Integr Comp Physiol 309:R1397-R1405. https://doi. org/10.1152/ajpregu.00315.2015

19. Roman RJ, Cowley AW Jr (1985) Abnormal pressure-diuresis-natriuresis response in spontaneously hypertensive rats. Am J Physiol 248:F199F205. https://doi.org/10.1152/ajprenal.1985.248.2.F199

20. Hsu CH, Chen PS, Caldwell RM (1984) Renal phosphate excretion in spontaneously hypertensive and normotensive Wistar Kyoto rats. Kidney Int 25:785-795. https://doi.org/10.1038/ki.1984.91

21. Bhatt DL, Kandzari DE, O'Neill WW, D'Agostino R, Flack JM, Katzen BT, Leon MB, Liu M, Mauri L, Negoita M, Cohen SA, Oparil S, Rocha-Singh K, Townsend RR, Bakris GL, for the SYMPLICITY HTN-3 Investigators (2014) A controlled trial of renal denervation for resistant hypertension. N Engl J Med 370:1393-1401. https://doi.org/https://doi.org/10.1056/NEJMo a1402670

22. Sata Y, Head GA, Denton K, May CN, Schlaich MP (2018) Role of the sympathetic nervous system and its modulation in renal hypertension. Front Med (Lausanne) 5:82. https://doi.org/10.3389/fmed.2018.00082

23. Böhm M, Kario K, Kandzari DE, Mahfoud F, Weber MA, Schmieder RE, Tsioufis K, Pocock S, Konstantinidis D, Choi JW, East C, Lee DP, Ma A, Ewen S, Cohen DL, Wilensky R, Devireddy CM, Lea J, Schmid A, Weil J, Agdirlioglu T, Reedus D, Jefferson BK, Reyes D, D'Souza R, Sharp ASP, Sharif F, Fahy M, DeBruin V, Cohen SA, Brar S, Townsend RR, on behalf of the SPYRAL HTN-OFF MED Pivotal Investigators (2020) Efficacy of catheter-based renal denervation in the absence of antihypertensive medications (SPYRAL HTN-OFF MED Pivotal): a multicentre, randomised, sham-controlled trial. Lancet 395:1444-1451. https://doi.org/https://doi. org/10.1016/S0140-6736(20)30554-7

24. Blankestijn PJ, Meijvis SC (2020) Renal denervation: time to refine the focus of research. Lancet 395:p1404

25. Gao J, Kerut EK, Smart F, Katsurada A, Seth D, Navar LG, Kapusta DR (2016) Sympathoinhibitory effect of radiofrequency renal denervation in spontaneously hypertensive rats with established hypertension. Am J Hypertens 29:1394-1401. https://doi.org/10.1093/ajh/hpw089

26. Kline RL, Kelton PM, Mercer PF (1987) Effect of renal denervation on the development of hypertension in spontaneously hypertensive rats. Can J Physiol Pharmacol 65:1540-1547. https://doi.org/10.1139/y87-243 
27. Wang M, Han W, Zhang M, Fang W, Zhai X, Guan S, Qu X (2018) Longterm renal sympathetic denervation ameliorates renal fibrosis and delays the onset of hypertension in spontaneously hypertensive rats. Am J Trans Res 10:4042-4053

28. Bianchi G, Fox U, Di Francesco GF, Giovanetti AM, Pagetti D (1974) Blood pressure changes produced by kidney cross-transplantation between spontaneously hypertensive rats and normotensive rats. Clin Sci Mol Med 47:435-448. https://doi.org/10.1042/cs0470435

29. Jose PA, Eisner GM, Drago J, Carey RM, Felder RA (1996) Dopamine receptor signaling defects in spontaneous hypertension. Am J Hypertens 9:400-405. https://doi.org/10.1016/0895-7061(95)00351-7

30. Yoshimura M, Kambara S, Takahashi H, Okabayashi H, ljichi H (1987) Involvement of dopamine in development of hypertension in spontaneously hypertensive rat: effect of carbidopa, inhibitor of peripheral dopa decarboxylase. Clin Exp Hypertens A 9:1585-1599. https://doi.org/10. 3109/10641968709159004

31. Bo Xu, Zheng H, Liu X, Patel KP (2015) Activation of afferent renal nerves modulates RVLM-projecting PVN neurons. Am J Physiol Heart Circ Physiol 308:H1 103-H1111. https://doi.org/10.1152/ajpheart.00862.2014

32. Huang BS, Van Vliet BN, Leenen FHH (2004) Increases in CSF $\left[\mathrm{Na}^{+}\right]$precede the increases in blood pressure in Dahl S rats and SHR on a high-salt diet. Am J Physiol Heart Circ Physiol 287:H1 160-H1 166. https://doi.org/ 10.1152/ajpheart.00126.2004

\section{Publisher's Note}

Springer Nature remains neutral with regard to jurisdictional claims in published maps and institutional affiliations.
Ready to submit your research? Choose BMC and benefit from:

- fast, convenient online submission

- thorough peer review by experienced researchers in your field

- rapid publication on acceptance

- support for research data, including large and complex data types

- gold Open Access which fosters wider collaboration and increased citations

- maximum visibility for your research: over $100 \mathrm{M}$ website views per year

At BMC, research is always in progress.

Learn more biomedcentral.com/submissions 